British Journal of Ophthalmology, 1980, 64, 565-575

\title{
Pattern of mortality in choroidal malignant melanoma
}

\author{
R. B. S. PACKARD \\ From the Institute of Ophthalmology, Moorfields Eye Hospital, London
}

SUMMARY A large series of cases of malignant choroidal melanoma has been reviewed. Certain risk factors have been related to prognosis by means of actuarial life tables. With information from these tables to calculate mortality rates graphs were drawn for various risk factors to demonstrate the differing pattern in tumours of varying size, degree of pigment, position of anterior border, etc. Further, a discriminant analysis was carried out in relation to differing cell types of tumour. It was concluded that tumour size overall was most important for assessing prognosis, and for small tumours the type of treatment seems not to influence survival. The presence of an early mortality peak is found, as suggested in other series, but a second peak is also present. A possible cause of this later peak is suggested.

Since the earliest descriptions of pigmented tumours at the beginning of the 19th century, ${ }^{1}$ and of ocular tumours of this nature in particular, controversy has existed as to the histogenesis, behaviour, clinical course, and treatment of choroidal malignant melanoma. The most recent of these disputes has been that arising from the publications by Zimmerman and colleagues. ${ }^{2-4}$ These writers having initially stated that 'It cannot be concluded that there is a group of favourable cases (of malignant choroidal melanoma) for which enucleation is excessive treatment'. Then in a later article they looked again at the data of Paul et al..$^{5}$ From this new analysis they arrived at certain impressions: (1) that the mortality rate before enucleation is low, (2) that the mortality rate rises abruptly following enucleation, (3) that approximately two-thirds of the fatalities could be attributed to the dissemination of tumour emboli at the time of enucleation. ${ }^{3}$ In a subsequent article ${ }^{4}$ these writers expanded on the evidence to support these postulates.

As part of a study ${ }^{8}$ of a large series of choroidal malignant melanomas which was under way at the Institute of Ophthalmology at this time I subjected our available data to a more exhaustive examination of mortality patterns. This was in an attempt to throw further light if possible on this matter. New material will also be presented here in relation to the type of treatment used and its effect on mortality.

Correspondence to Mr R. B. S. Packard, Charing Cross Hospital, Fulham Palace Road, London W6.

\section{Material and methods}

The cases of malignant melanoma of the choroid on which this study was based were those seen and treated at Moorfields Eye Hospital between 1949 and 1972. By not including any more recent cases a minimum period of 5 years' follow-up was possible. This follow-up was carried out at Moorfields Eye Hospital at the City Road or High Holborn Branches, or by the referring hospital, or, finally, by letter via the patient's general practitioner. In those cases that died the cause of death was either discovered directly from the Cancer Registry at the Institute of Ophthalmology following notification by the hospital or general practitioner concerned, or in some cases a relative supplied notification of death and later the cause was sought from the Registrar General's records. All available information regarding the patients was stored in the card index of the Cancer Registry at the Institute of Ophthalmology.

In cases where the information was incomplete with regard to such things as length of history prior to treatment the patient's notes were obtained from the files at Moorfields Eye Hospital. By far the largest part of the series consisted of patients who had been treated by enucleation as a primary procedure. The total number of cases was 578, of whom 506 had had enucleation. Of these 506 patients $484 \mathrm{had}$ their enucleations as a primary procedure, and 22 patients initially treated conservatively had either had continued tumour growth or complications from their treatment which had made enu- 
cleation necessary. As well as using the information obtained as above, the slides from the specimens obtained from these cases were examined to determine various pathological parameters which will be mentioned shortly. Between these 3 sources a reasonably full picture of the cause of the disease and its manifestations in individual cases could be reached for most patients.

In my thesis the following risk factors were analysed in a univariate and multivariate manner using the computer facilities at the University of London in order to try to determine the influence, if any, of individual factors on each other and the relationship of different factors to prognosis. These last factors in relation to prognosis will be considered in this paper. They were divided as follows:

(a) Clinical features. (i) Age of the patient at the time of treatment in years. (ii) The sex of the patient. (iii) The eye involved. (iv) The duration of history in months to the point of treatment. ( $v$ ) The presence or absence of a blind, painful eye at the time of primary treatment.

(b) Macroscopical features of the tumour. (i) The largest dimension of the tumour (LTD) in millimetres was measured on the largest section available. (ii) The anterior and (iii) posterior margins of the tumour were noted on similar sections. This was divided into 3 groups $(a)$ ciliary body to ora serrata, $(b)$ ora serrata to equator, (c) posterior to equator.

(c) Microscopical features of the tumour. (i) The cell type of the tumour was determined according to the classification current at the Institute of Ophthalmology and consisting of A-pure and predominantly spindle cell tumours; B-mixed cell tumours where one-third or more cells were epithelioid in type, the rest being spindle; $\mathrm{C}$-pure and predominantly epithelioid tumours; D-tumours so necrotic that accurate classification was impossible, though, as will be seen this in fact represents a very small percentage of the series as a whole. Such a classification first described by Ashton ${ }^{7}$ is very similar to that used by Raivio. ${ }^{8}$ (ii) Pigmentation was divided into 4 groups: A-amelanotic tumours or those with only a few widely scattered spots of pigment; B-lightly pigmented tumours where about $25 \%$ of the cells were obscured; C-if $50 \%$ of cells were obscured this was moderately pigmented; D-heavy pigmentation where $75 \%$ of the cells or more were unable to be seen without bleaching the section.

(iii) Reticulin fibre content was noted and classified in 4 groups. Wilder'ss taining technique was used here. A-no reticulin fibre present between cells; B-light fibre content where $25 \%$ of the cells were surrounded; C-moderate content if $50 \%$ of cells were surrounded; D-heavy content if more than $75 \%$ of cells have reticulin surrounding them. (iv) Scleral extension was found most convenient for division into 4 also. A-no extension or only a minimal amount; B-quarter to half thickness extension; C-greater than half thickness extension; $\mathrm{D}$-espiscleral extension. (v) Optic nerve extension was assessed, but the numbers involved were very small and no useful conclusions could be drawn from these data. (vi) The state of Bruch's membrane, that is, whether ruptured or intact, was also noted.

(d) Therapeutic features. The next group of risk factors related to various aspects of treatment. The patients were divided into those having primary or secondary enucleation and those being treated conservatively. The vast majority of this latter group had treatment with local irradiation using radioactive plaques. It was hoped in the light of the report from Shammas and Blodi ${ }^{9}$ that the role of exenteration might be determined, but so few patients were treated in this way that no useful conclusions could be reached for this series.

In order to study prognosis, the survival time both from the start of the clinical history and from the moment of primary treatment were noted. The date taken for those patients who had not died to determine their survival was the end of 1977. Thus the status of patients at that date has been divided as follows: A-alive; B-dead from metastases from choroidal malignant melanoma; $\mathrm{C}$-death from metastases from tumours other than malignant melanoma; D-death from causes not related to cancer.

After this, the prognosis was assessed in various ways. Firstly, cross-tabulation of various factors was undertaken against actual and percentage outcome in each case and an assessment of statistical significance using the chi-square test. In a second method, life tables were constructed as suggested by Berkson and Gage $^{10}$ to allow the percentage survival after $\mathrm{x}$ years to be calculated with provision being made in the survival date for patients withdrawn due to death from other causes. By using these tables calculated for the various factors under consideration, their influence on prognosis may be seen in a univariate manner. Also the relationship to time and pattern of mortality can be noted in each instance. As well as the univariate analysis certain multivariate prognostic analyses were also made.

The data obtained by these means were put into graphical form in 2 ways-firstly to show the percentage survival in the years of the study and secondly to show changing percentage mortality, that is, the chances of dying in any year following the primary treatment. This latter part of the study 
was similar to that carried out by Zimmerman $e t \mathrm{al}^{3}$ and also Benjamin et al. ${ }^{11}$ and Jensen, ${ }^{12}$ but the data under consideration were analysed in this manner for many different parameters.

\section{Results}

TOTAL NUMBERS

As already stated the series consisted of 578 patients with malignant choroidal melanoma. These were divided as follows as regards treatment: group I, primary enucleation, 484 patients $(83.7 \%)$; group II, primary conservative with later enucleation, 22 patients $(3.8 \%)$; group III, primary conservative, 72 patients $(12 \cdot 5 \%)$.

Of the group III patients, only 2 patients were observed with no treatment mode being employed, both of these patients died-one of unrelated causes and one who had presented with established melanoma metastatic disease died from these metastases. There were 2 other patients in the series as a whole who had established metastatic disease with a choroidal melanoma as the assumed primary at the time of diagnosis.

\section{PROGNOSIS}

Although as part of the doctoral thesis on which this paper is based prognosis was assessed by both cross-tabulations of risk factors in a single and multiple variate manner, the results were considered not as useful as those obtained by the use of actuarial life tables, and these alone will be presented here. This method allowed for the cases being withdrawn because of death from other causes and also for patients who were not followed up for the whole period under review to be included. This actuarial method of assessing outcome was also used by Shammas and Blodi. ${ }^{9}$ It has the added value of providing not only figures for survivors but also the chances of a patient dying in any given year following primary treatment. Using this method also will avoid any criticisms of the sort levelled by Siegel et al..$^{13}$ at Zimmerman and McLean ${ }^{4}$ for their use of statistics from Paul et al. ${ }^{5}$

Whole series. With the use of life tables as shown in Table 1 the series as a whole was assessed. The actuarial survival curves will be considered first. It will be seen from the graph (Fig. 1) that the overall survival rates were $78.7 \%$ at 5 years, $66.2 \%$ at 10 years, and $61 \%$ at 15 years. This is somewhat better than the figures of Paul et al. ${ }^{5}$ who used an actuarial method of calculating their results $(71 \%$ at 5 years, $60 \%$ at 10 years, and $46 \%$ at 15 years). It will be seen when Fig. 1 is considered also that the nonenucleated group fared rather better than the enucleated group. The reasons for this will be
Table 1 Life table for survival after treatment all patients

\begin{tabular}{|c|c|c|c|c|c|c|}
\hline \multirow{2}{*}{$\begin{array}{l}\text { Interval } \\
\text { in } \\
\text { years }\end{array}$} & \multicolumn{2}{|c|}{$\begin{array}{l}\text { During } \\
\text { interval }\end{array}$} & \multirow{2}{*}{$\begin{array}{l}\text { Living } \\
\text { at start } \\
\text { interval }\end{array}$} & \multirow{2}{*}{$\begin{array}{l}\text { Adjusted } \\
\text { no. at } \\
\text { risk }\end{array}$} & \multirow{2}{*}{$\begin{array}{l}\text { Prob. } \\
\text { of death } \\
\text { from } \\
M M\end{array}$} & \multirow{2}{*}{$\begin{array}{l}\text { Percentage } \\
\text { survivors } \\
\text { at end of } \\
\text { interval }\end{array}$} \\
\hline & Died & $\begin{array}{l}\text { With- } \\
\text { drawn }\end{array}$ & & & & \\
\hline $0-$ & 15 & 7 & 576 & 573 & 0.0262 & $97 \cdot 4$ \\
\hline $1-$ & 22 & 4 & 554 & 552 & 0.0399 & 93.5 \\
\hline $2-$ & 31 & 8 & 528 & 524 & 0.0592 & 88.0 \\
\hline $3-$ & 34 & 8 & 489 & 485 & 0.0701 & $81 \cdot 8$ \\
\hline 4 & 17 & 8 & 447 & 443 & 0.0384 & 78.7 \\
\hline $5-$ & 14 & 34 & 422 & 405 & 0.0346 & 75.9 \\
\hline $6-$ & 13 & 19 & 374 & 365 & 0.0357 & $73 \cdot 2$ \\
\hline $7-$ & 7 & 30 & 342 & 327 & 0.0214 & $71 \cdot 7$ \\
\hline $8-$ & 10 & 14 & 305 & 298 & 0.0336 & $69 \cdot 3$ \\
\hline $9-$ & 12 & 22 & 281 & 270 & 0.0444 & $66 \cdot 2$ \\
\hline $10-$ & 4 & 25 & 247 & 235 & 0.0171 & $65 \cdot 1$ \\
\hline $11-$ & 2 & 28 & 218 & 204 & 0.0098 & 64.4 \\
\hline $12-$ & 4 & 20 & 188 & 178 & 0.0225 & 63.0 \\
\hline $13-$ & 1 & 24 & 164 & 152 & 0.0066 & 62.6 \\
\hline 14 & 3 & 20 & 139 & 129 & 0.0233 & $16 \cdot 1$ \\
\hline $15-$ & 2 & 21 & 116 & 106 & 0.0190 & 59.9 \\
\hline $16-$ & 4 & 13 & 93 & 87 & 0.0462 & 57.2 \\
\hline $17-$ & 1 & 8 & 76 & 72 & 0.0139 & 56.4 \\
\hline $18-$ & 0 & 10 & 67 & 62 & 0.0 & 56.4 \\
\hline $19-20$ & 1 & 14 & 57 & 50 & 0.0200 & $55 \cdot 2$ \\
\hline
\end{tabular}

$\mathbf{M M}=$ malignant melanoma.

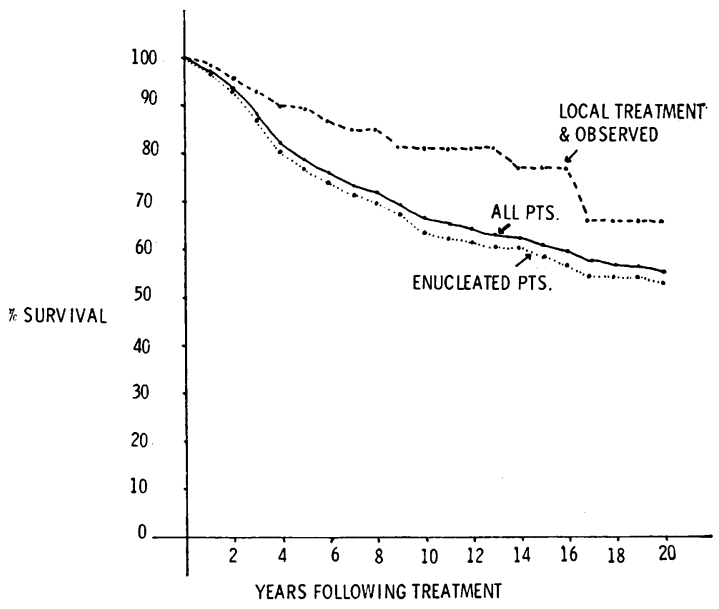

Fig. 1 Actuarial survival curve for patients with choroidal malignant melanoma.

discussed below.

Sex. There was a small survival difference between the sexes in that males seemed to survive better (at 10 years, males $69.2 \%$ and females $62.2 \%$ survival) than the females. There is no very ready explanation for this except possibly the higher incidence of heavy pigmentation in the older females. No similar relationship was found by Paul 


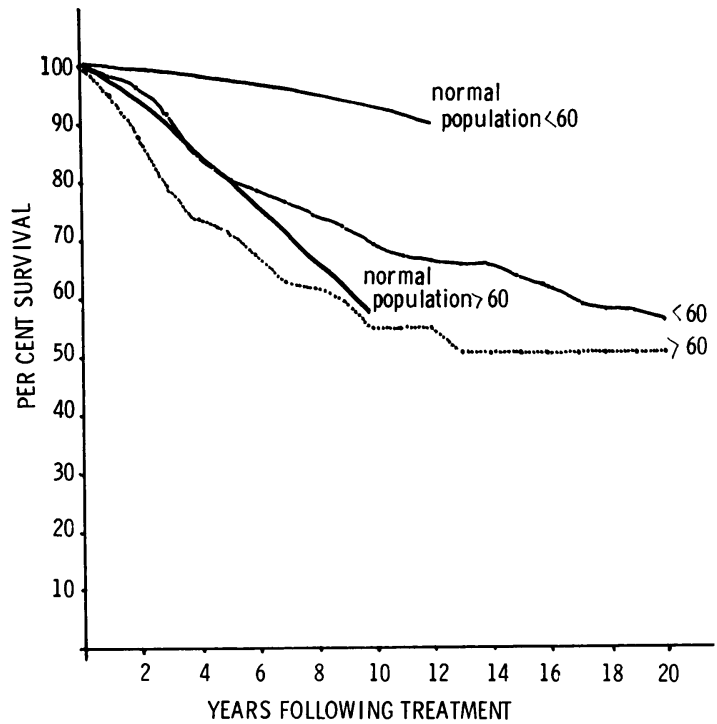

Fig. 2 Actuarial survival curve for patients with choroidal malignant melanoma over and under 60 years age groups.

et al..$^{5}$ or Shammas and Blodi. ${ }^{9}$

Age. If the population under review is divided into groups over and under 60 years of age (Fig. 2) there is a general trend for those patients under 60 years of age to survive better. However, if the normal actuarial survival for the whole population is introduced, it will be seen that, while survival in the over 60s approaches that of a normal population, that of the younger group is much different. This would suggest that malignant choroidal melanoma is a more important factor in shortening life in patients under than over 60 years. This point will be clarified further when various other parameters are considered in conjunction with age.

Duration of history. On the duration of history the patients were divided into 2 groups, those with a history less than 1 year and those with a history of 1 year or more. The survival for both groups at 5,10 , and 15 years is really very similar for the 2 groups being at these 3 points, namely, $77.7 \%, 64.9 \%$, and $60.8 \%$ for those with a shorter history and $74.5 \%, 60.9 \%$, and $58.6 \%$ for the patients with a longer history.

Size. As already mentioned, tumours were divided for size into small, medium, and large. A survival curve (Fig. 3) shows the dramatic difference between these 3 groups.

Position of anterior border. If the position of the anterior border is divided simply into those with this border in front of and those behind the equator, there is a striking difference in survival. At 10 years patients with anterior tumours have a $43.9 \%$ survival, while those with anterior borders posterior to the equator have a survival of $76.5 \%$. These figures refer only to those patients who had undergone enucleation.

Cell type. Cell type of the tumour when assessed for prognosis Fig. 4 shows that spindle cell tumours have a much better prognosis $(85 \%$ survival at 5 years) than either the mixed $(58 \%$ at 5 years $)$ or

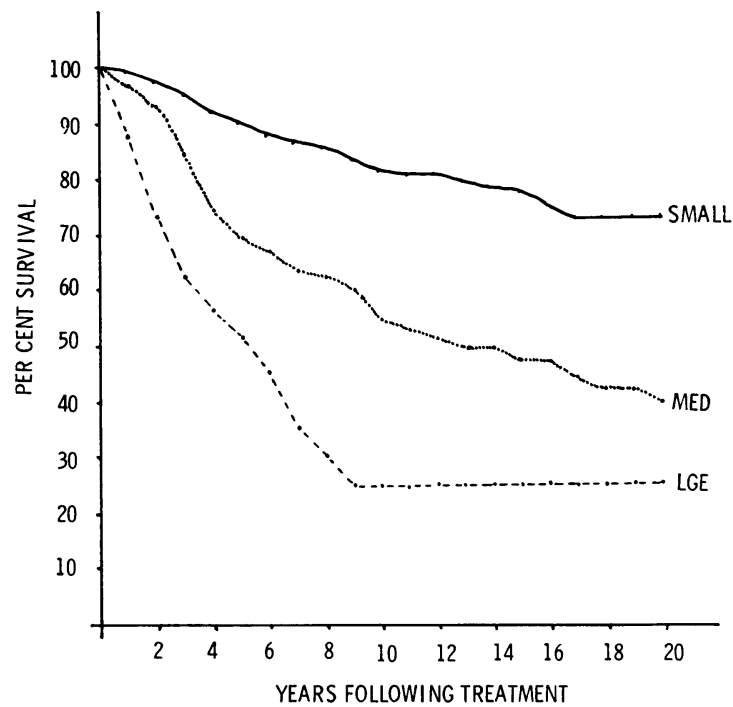

Fig. 3 Actuarial survival curve of patients with choroidal malignant melanoma for tumour size.

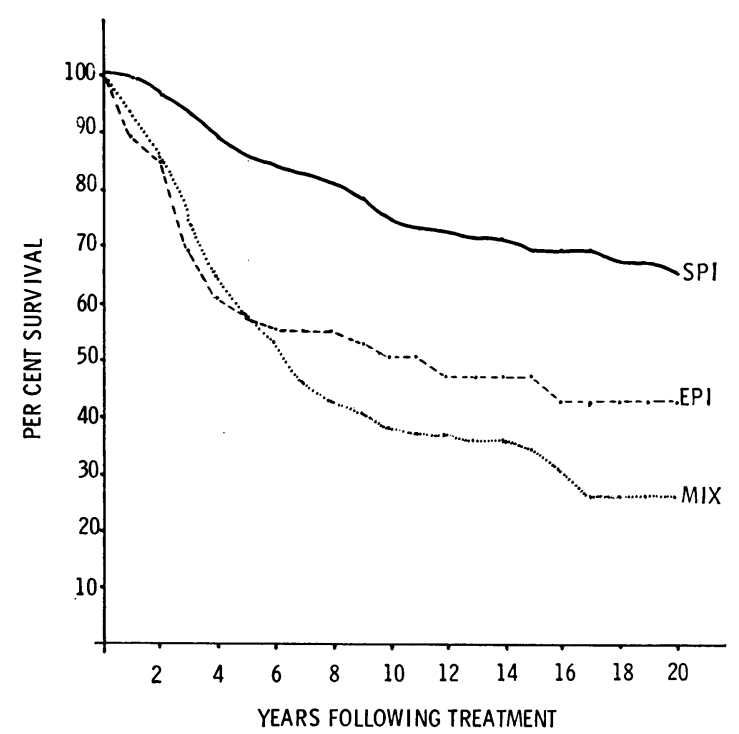

Fig. 4 Actuarial survival curve for patients with choroidal malignant melanoma for cell type. 
epithelioid ( $57 \%$ at 5 years). The figures at 10 years suggest that patients with mixed cell tumours fare worse than those with epithelioid tumours. This is because epithelioid tumours in this series are relatively a small number and also they tend to occur in older patients. Thus this group was subject to a higher mortality from causes other than the tumour under discussion here.

Pigment content. Consideration of the level of pigmentation shows how much worse is the prognosis if the amount of melanin in the tumour is heavy. At 10 years the survival in these patients is $38.8 \%$ as compared to more than $75 \%$ in both amelanotic and lightly pigmented tumours.

Reticulin fibre content. In my thesis ${ }^{6}$ I found that for various risk factors there were no useful correlations for reticulin content. Indeed for prognosis an entirely different result from that found in other series is demonstrated with no reticulin $(83.6 \%$ survival) given a better prognosis than heavy reticulin $(53.9 \%$ survival) at 10 years. However, as will be seen later in the discriminant analysis, reticulin is not useful as a prognostic factor.

Scleral extension. This factor shows a marked difference between the increasing degrees of scleral extension (Fig. 5). Survival for those patients with no extension is really quite good $(89.7 \%$ at 5 years, $81.7 \%$ at 10 years, and $76.4 \%$ at 15 years) as compared to patients with episcleral extension $(42.3 \%$ at 5 years, $23.8 \%$ at 10 years, and $21.4 \%$ at 15 years). In fact all those patients who will die from their tumour are dead within 11 years of primary treatment where episcleral extension is present.

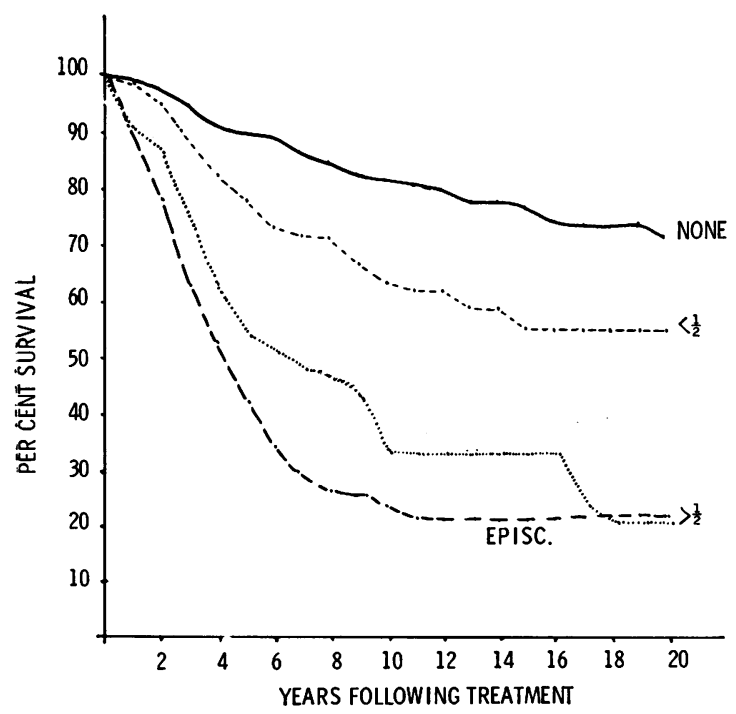

Fig. 5 Actuarial survival curve for patients with choroidal malignant melanoma for scleral extension.
A series of life tables were then constructed and graphs drawn from these to assess the influence of more than one factor on prognosis at any one time. Firstly age, either under or over 60 years at the time of primary treatment, was considered in relation to size, cell type, the presence of heavy pigment, and the presence of episcleral extension.

Age and size. The size of the tumour for the purposes of analysis here was recorded as being either less than or greater than $10 \mathrm{~mm}$ largest tumour diameter. When these 2 groups are combined with the 2 age groups plotted on a graph survival of both small tumour groups was very similar $(83.5 \%$ at 10 years for the under $60 \mathrm{~s}$ and $81.5 \%$ for the over $60 \mathrm{~s})$. The large tumour groups, however, had as expected a much worse prognosis, and the older patients of these 2 did the worst (54.3\% survival at 10 years for the under $60 \mathrm{~s}, 42 \cdot 2 \%$ for the over $60 \mathrm{~s}$ ).

Age and cell type. A similar situation was found when cell type and age were considered in relation to prognosis in that spindle cell tumours in both age groups do quite well (at 10 years under 60 s $76.4 \%$ survival, over $60 \mathrm{~s} 69.4 \%$ ) and mixed and epithelioid tumours (considered as one group) do considerably worse with the older patients surviving least well (at 10 years under 60 s $49.9 \%$ survival, over 60 s $24 \cdot 4 \%$ ).

Age and heavy pigment content. In this instance the difference between the age groups is quite large though in both the prognosis is poor (at 10 years, $47.5 \%$ survival for the under 60 s and $27.0 \%$ survival for the over $60 \mathrm{~s}$ ).

Age and episcleral extension. All patients, as has been shown, have poor prognosis in this group, and the difference in survival seems unrelated to age, being at 10 years $23 \%$ for under 60 s and $24 \%$ for over $60 \mathrm{~s}$.

State of Bruch's membrane. The state of Bruch's membrane when considered in isolation appears to have a profound effect on prognosis, i.e., at 10 years survival of $80.8 \%$ for those patients with an intact membrane and $55.8 \%$ where it is ruptured. In fact if the relationship of size to the state of Bruch's membrane is remembered, then the survival figures are almost certainly a function of the difference in size of the 2 tumour groups, Bruch's membrane intact and ruptured.

Next, size in the 2 groups as already mentioned and the variable cell type, presence of heavy pigmentation, and presence of episcleral extension were related in a life table and graphical form.

Size and cell type. In this combination it can be seen that, although size is very important within the different cell types themselves, mixed cell and epithelioid tumours have a worse prognosis than those with predominantly spindle cells. It is interesting 


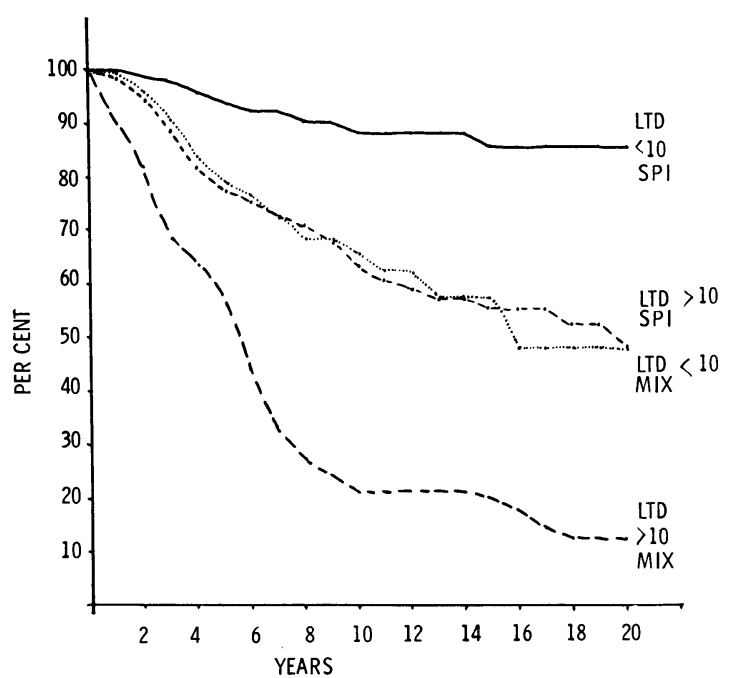

Fig. 6 Actuarial survival curve of patients with choroidal malignant melanoma when size and cell type are taken against prognosis.

that the larger spindle cell tumours and the smaller mixed cell tumours have an almost identical prognosis (Fig. 6).

Size and heavy pigment. Size showed itself to be important when taken with heavy pigment in that smaller tumours had a much better prognosis, i.e., $61 \%$ survival at 10 years as opposed to $27 \%$ for the larger tumours.

Size and episcleral extension. There was no such obvious difference between the size groups here, though whether this is a true relationship is uncertain because of the small numbers involved in the small size group with episcleral extension.

During the period that the doctoral thesis on which this study is based ${ }^{6}$ was being compiled, the ideas of Zimmerman et al. as first published in 1978 prompted a similar type of investigation into mortality rates using the present data.

The writers just mentioned had re-examined the data of Paul et al..$^{5}$ and reworked them so that the rate of mortality from malignant choroidal melanoma was calculated in each year following primary treatment. In the cases used in their data their patients had all had enucleation. Zimmerman et al. $^{3}$ and Zimmerman and McLean ${ }^{4}$ have postulated that, because these tumours had been growing for varying lengths of time prior to diagnosis, and in view of the seemingly similar prognosis after enucleation despite the length of history, combined with the knowledge of the rarity of metastasis being observed prior to enucleation, the peak in mortality rates which they have demonstrated in the years immediately following enucleation may in some way be connected to this form of treatment. They felt that this rise in the mortality rate was due to dissemination of malignant cells at the time of surgery. Later writers ${ }^{13}$ have questioned firstly the existence of this mortality peak, by pointing out the inaccurate (statistically speaking) use of data by Zimmerman and colleagues and then the unique nature of this curve in relation to malignant choroidal melanoma. In view of these conflicting views I felt that the study I had undertaken could help to throw some further light on this vexed matter.

Accordingly graphs were drawn from the life tables used to calculate the survival data. This was done not only for the series as a whole, but also for various single and combinations of risk factors thus allowing a closer assessment of the influence of these factors on the time course of prognosis.

In the first graph (Fig. 7) is recorded the annual likelihood of mortality for the whole series, enucleated patients and those treated by conservative means.

Considering the whole series in the first instance, there would appear to be 2 peaks in mortality-one at 3-4 years following treatment and the other at 9-10 years. A similar shaped graph is obtained from those patients undergoing enucleation, but for the patients treated conservatively a much less definite pattern is seen. Although Zimmerman et al. ${ }^{4}$ chose to ignore the second peak, it is present on their graph and also that of Benjamin et al. ${ }^{11}$ and Jensen. ${ }^{12}$ The significance of the second peak will be discussed below.

The following risk factors were analysed individually to assist the influence on mortality rates which they might have and to demonstrate the

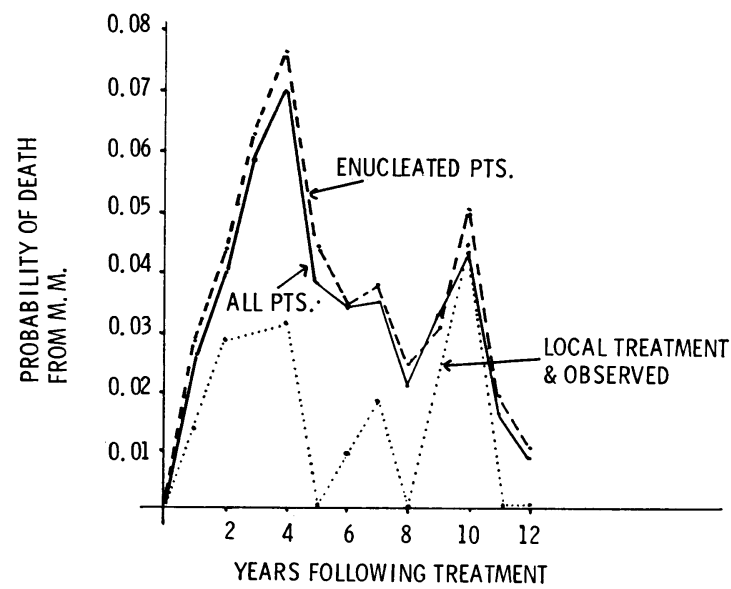

Fig. 7 Probability graph for death from choroidal malignant melanoma for all treatment groups. 
varying patterns for different tumours-duration of history, position of the anterior border, tumour size, cell type, scleral extension; also age, at greater or less than 60 years in the presence of tumours larger or smaller than $10 \mathrm{~mm}$ (Figs. 8, 9, 10, 11, 12, 13).

The duration of history was for those patients with histories less than or more than 1 year. As can

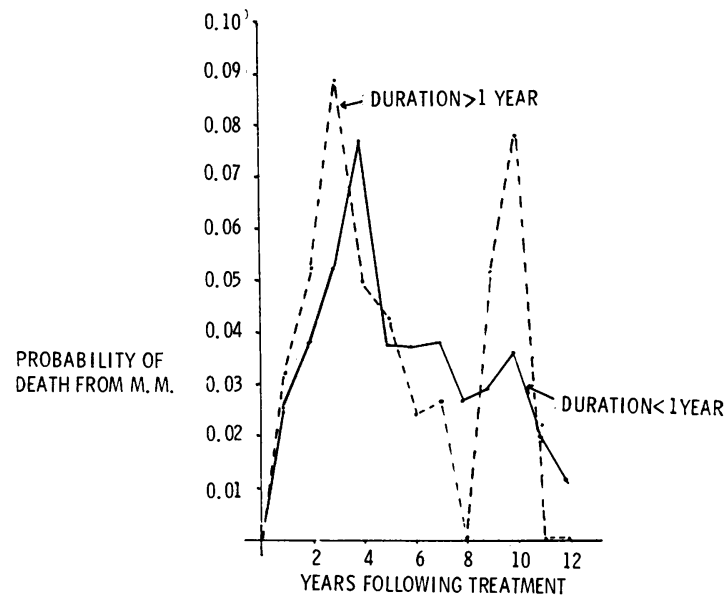

Fig. 8 Probability graph for death from choroidal malignant melanoma for duration of history.

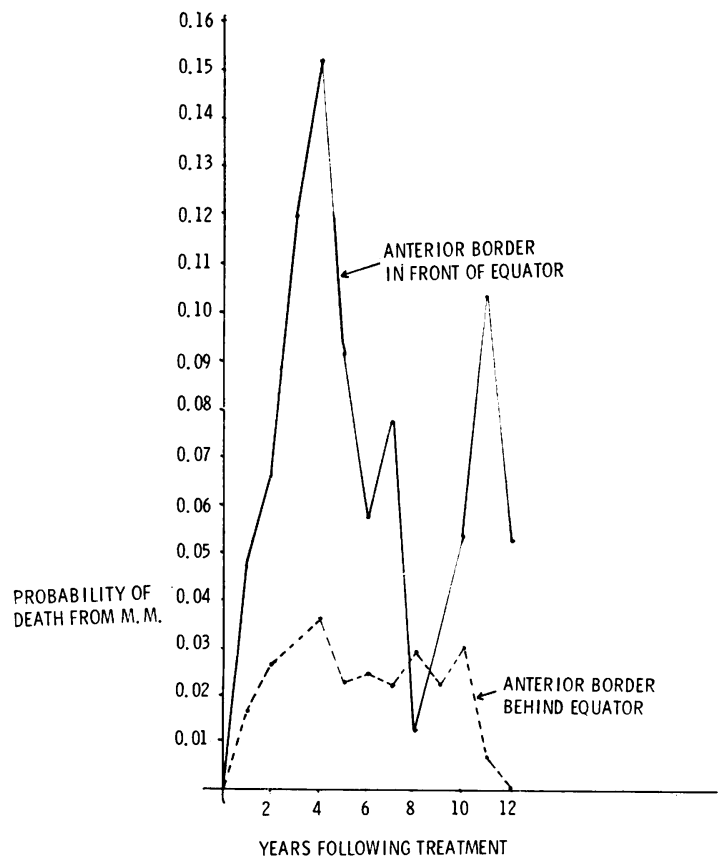

Fig. 9 Probability graph for death from choroidal malignant melanoma for position of the anterior border of the tumour.

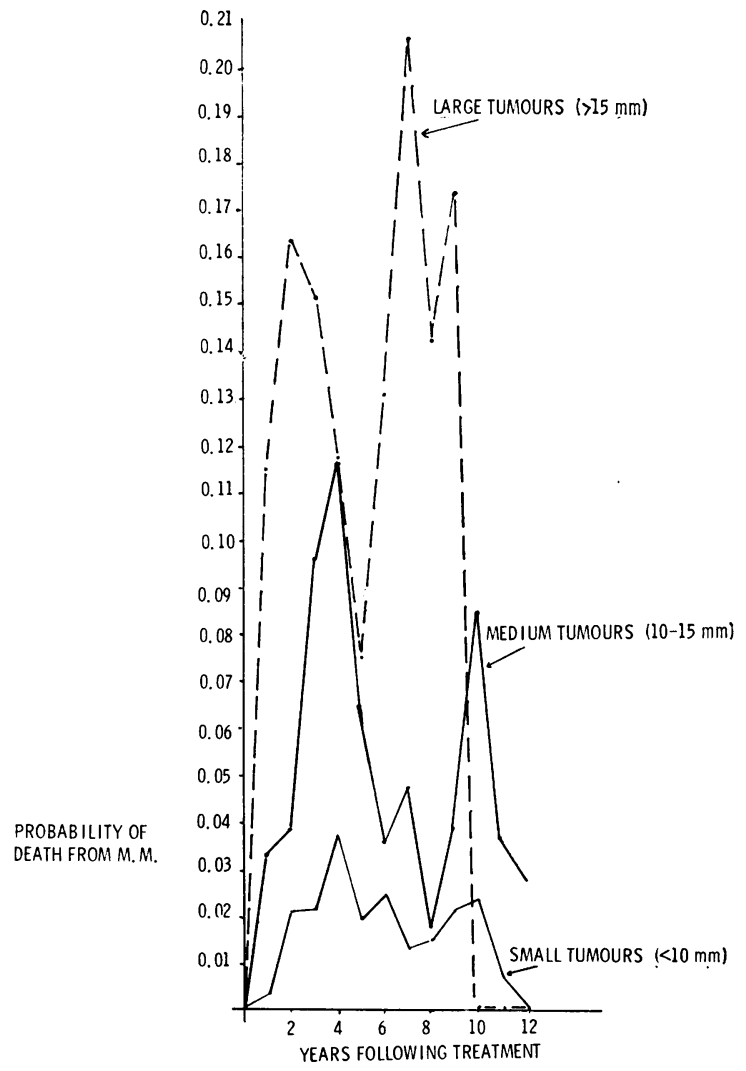

Fig. 10 Probability graph for death from choroidal malignant melanoma for tumour size.

be seen the mortality peak occurred 1 year earlier in those patients with the longer history. This was probably related to the patient's age more than anything else, because we know that the over 60 s tend to have longer histories and they also have an earlier mortality peak.

Tumours with anteriorly placed borders have a much more dramatic mortality pattern than those with this border posterior to the equator (Fig. 9). In fact the pattern for these posterior tumours was very similar to that for small tumours (Fig. 10) spindle cell tumours (Fig. 11) and tumours with no extension (Fig. 12), also with the tumours treated by conservative means. This similarity is not surprising, as small tumours tend to be spindle celled, posteriorly placed, with less extension, and are more likely to be the type treated conservatively. ${ }^{6}$

The dramatic rises in probability of death particularly seen for large tumours, those with epithelioid cells present, and those which have their sclera excessively invaded or perforated speak for themselves by comparison. The factors which may influence these graphs will be discussed below. 


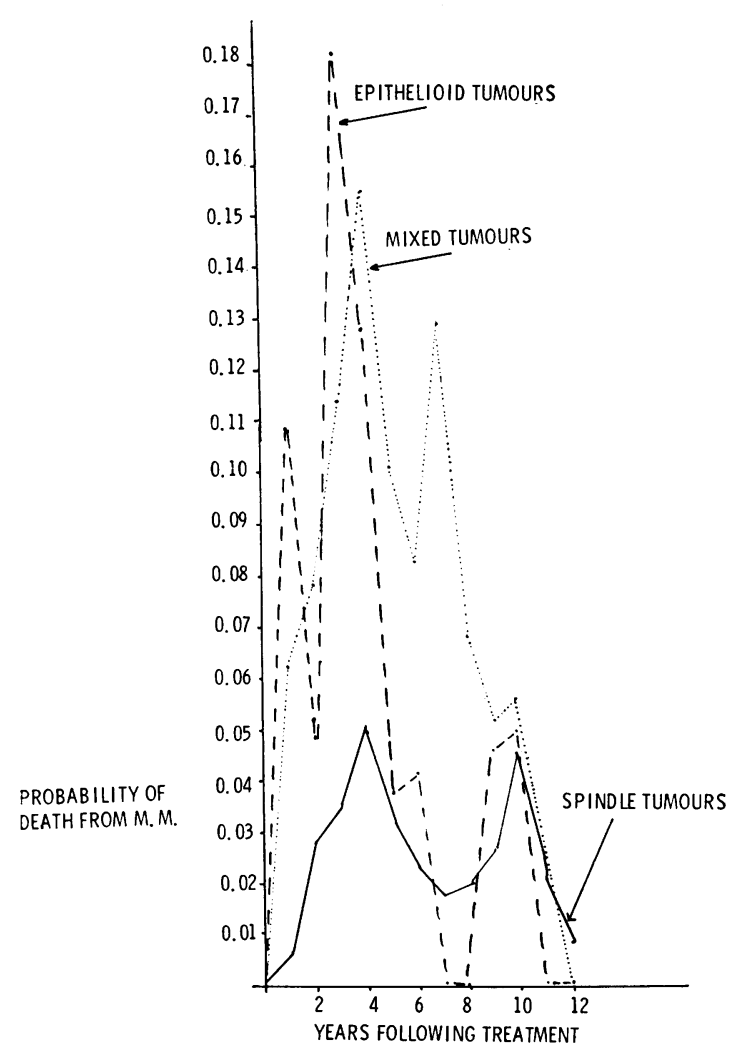

Fig. 11 Probability graph for death from choroidal malignant melanoma for cell type.

In order to assist further in the assessment of individual cases a discriminative analysis was carried out. Initially this was done in the linear manner suggested by McLean et al. ${ }^{2}$ However, it was felt that cell type could not truly be assessed in such a manner as it implied that spindle cell tumours were necessarily of better prognosis than epithelioid tumours and mixed cell tumours somewhere in between. To give a more accurate picture the 3 cell types were assessed in this manner separately. Certain risk factors, notably pigment, were found to have a different influence in different cell type tumours. McLean et al. $^{2}$ felt that this finding in spindle cell tumours was due to misclassification of some of these tumours, which were really mixed cell type masked by pigment. However, if this were true, any prognostic value of pigmentation would be weakened in their analysis by the fact that mixed and spindle cell tumours were being considered together.

The results shown in Table 2 of the stepwise discriminant analysis suggest that the most important predictor for outcome is pigmentation in spindle
Table 2 Standardised discriminant function coefficients

\begin{tabular}{lcll}
\hline Variable & $\begin{array}{l}\text { Spindle } \\
(167)\end{array}$ & $\begin{array}{l}\text { Mixed } \\
(75)\end{array}$ & $\begin{array}{l}\text { Epithelioid } \\
(28)\end{array}$ \\
\hline LTD & -0.227 & -0.517 & -0.759 \\
Pigmentation & -0.369 & 0.197 & -0.155 \\
Reticulin & -0.196 & - & -0.389 \\
AB location & 0.236 & - & - \\
PB location & - & - & 0.232 \\
Age & -0.223 & -0.462 & - \\
Sex & - & -0.389 & -0.286 \\
Scleral extension & -0.260 & - & -0.162 \\
Neurovascular channel & - & -0.261 & -0.173 \\
$\quad$ extension & - & -0.215 & - \\
Bruch's membrane & -0.205 & & \\
& - & 0.267 & 0.336 \\
Duration & - & 74.17 & 103.56 \\
Final Rao's V & 96.34 & 0.496 & 0.200 \\
Willis lambda & 0.631 & 0.710 & 0.894 \\
Canonical corr. & 0.618 & & \\
\hline
\end{tabular}

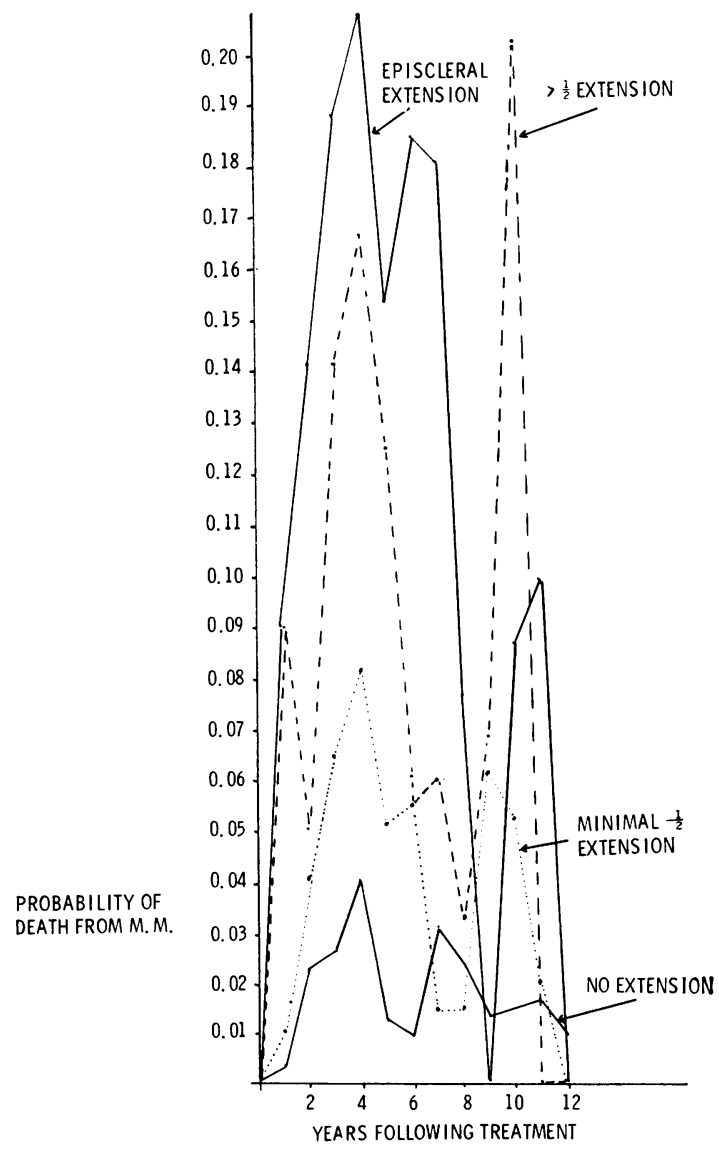

Fig. 12 Probability graph for death from choroidal malignant melanoma for scleral extension. 


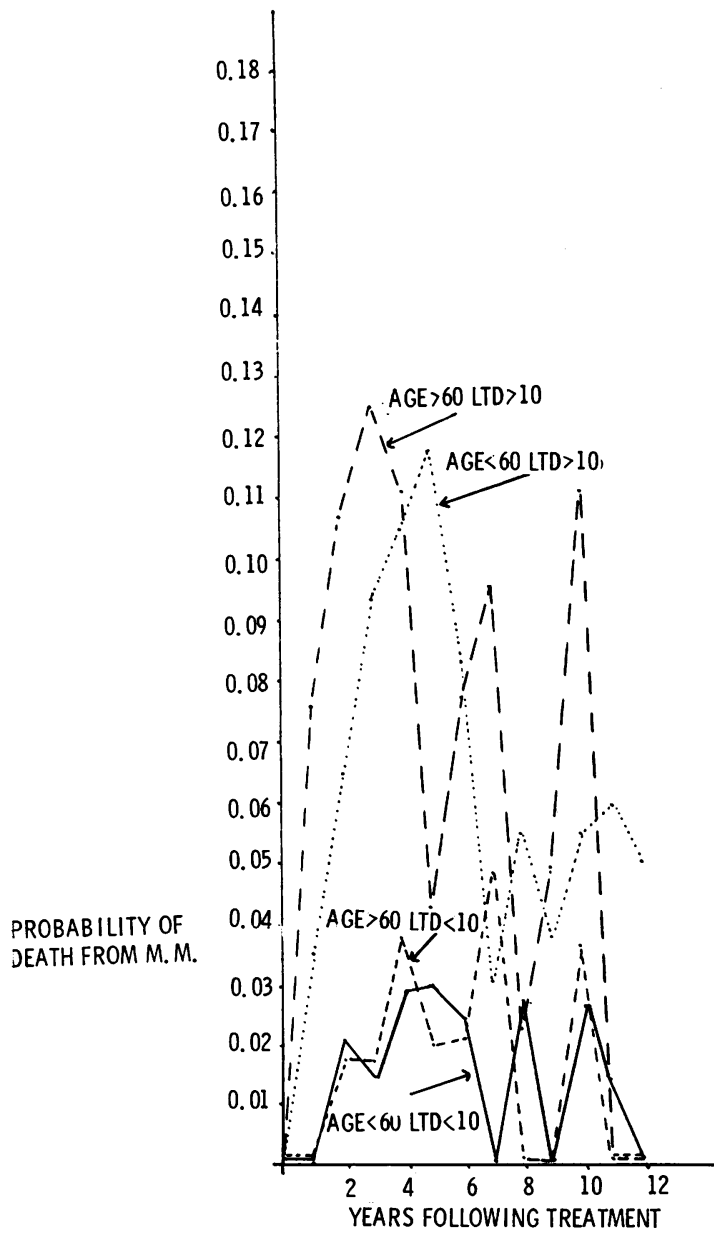

Fig. 13 Probability graph for death from choroidal malignant melanoma showing age in relation to size.

cell tumours and size in mixed and epithelioid tumours. It was hoped to be able to use this analysis for predicting outcome in individual cases, but results, even in this series, were disappointing with an accuracy of only $85 \%$. As McLean et al. ${ }^{2}$ have suggested, one set of data from a retrospective survey does not necessarily give useful or accurate answers when applied to another set of data. Also as this analysis is entirely from enucleated patients, it is of no use unless this type of treatment is to be used.

\section{Discussion}

It was shown in the thesis ${ }^{6}$ on which this paper is based how as age increases tumours are more likely to have a longer history, be larger, more anteriorly placed, not be spindle celled, be more pigmented particularly in females, have a greater degree of scleral extension, and a ruptured Bruch's membrane. However, it was also shown that large tumours per se are more often anterior, less likely to be spindle celled, have more pigment and scleral extension, and have a ruptured Bruch's membrane.

If the mortality patterns for the various factors are again reviewed it is obvious, for example, that as tumours get larger the survival worsens.

One similarity which should also be mentioned is between the 10-year survival in small enucleated tumours and those treated conservatively $(81.4 \%$ for small tumours, $81.3 \%$ for conservatively treated tumours). This would suggest that enucleation need have little place in the treatment of such tumours as a primary procedure while good vision may be maintained; also that there is no greater likelihood of tumour spread than if the tumour is removed completely. As will be seen when the rates of mortality in other groups are considered in relation to enucleation, no such comforting picture may be said to exist in these other cases.

While reviewing the work of Paul et al. ${ }^{5}$ Zimmerman et $a l^{3}$ noted certain points in the distribution of mortality, in relation to treatment by enucleation. This led these writers to postulate that this type of treatment might in fact be responsible for the peak in mortality which they demonstrated to occur 2 to 3 years after enucleation. The validity of this observation has been called into doubt by Siegel et al. ${ }^{13}$ but the data in the present series and those of Benjamin et al. ${ }^{11}$ and Jensen ${ }^{12}$ show that such a pattern undoubtedly does exist. In fact as stated earlier 2 peaks are present.

Zimmerman and McLean ${ }^{4}$ have offered an explanation for the first mortality peak. The presence of such a peak was supposed to be found in many malignancies treated by surgery and also by irradiation..$^{13}$ In fact, if one looks closely at Siegel et al.'s figures, the majority of the tumours which they cite either have no peak or have their highest mortality in the first post-treatment year, with death falling away in later years. Only in melanoma of the skin and breast carcinoma with regional involvement of the surgically treated cases and carcinoma of the cervix treated by irradiation is any similarity of pattern seen. We are not told whether the irradiation was administered by local insertion of radioactive materials in the patients with cervical carcinoma, which, if this were the case, would necessitate some local manipulation of the tumour.

The explanation of the second peak was at first hard to realise. It was possible that immunological factors were important, such that in those patients dying in the earlier peak they might be less able to cope with any outflow of metastatic cells from the 
Table 3 Numbers and percentages of patients dying in 1 st and 2nd 5-year postenucleation periods in each cell type group, excluding necrotic

\begin{tabular}{lccl}
\hline & 1st 5 years & 2nd 5 years & $\begin{array}{l}\text { Total patients } \\
\text { dying }\end{array}$ \\
\hline Spindle & $46(55.4 \%)$ & $29(34.9 \%)$ & 83 \\
Mixed & $46(63.9 \%)$ & $19(26.4 \%)$ & 72 \\
Epithelioid & $19(79.2 \%)$ & $3(12.5 \%)$ & 24 \\
\hline
\end{tabular}

Table 4 Percentage of patients with tumours of each cell type dying in each year after treatment

\begin{tabular}{llrrl}
\hline Year & Total & \multicolumn{1}{l}{ Spindle } & \multicolumn{1}{l}{ Mixed } & Epithelioid \\
\cline { 3 - 6 } $0-$ & 14 & $2(14.3 \%)$ & $7(50.0 \%)$ & $5(35.7 \%)$ \\
$1-$ & 20 & $9(45.0 \%)$ & $8(40.0 \%)$ & $2(10.0 \%)$ \\
$2-$ & 29 & $11(37.9 \%)$ & $11(37.9 \%)$ & $7(24.2 \%)$ \\
$3-$ & 32 & $15(46.9 \%)$ & $13(40.6 \%)$ & $4(12.5 \%)$ \\
$4-$ & 17 & $9(52.9 \%)$ & $7(41.2 \%)$ & $1(5.5 \%)$ \\
$5-$ & 12 & $6(50.0 \%)$ & $5(41.66 \%)$ & $1(8.33 \%)$ \\
$6-$ & 12 & $4(33.3 \%)$ & $7(58.33 \%)$ & 0 \\
$7-$ & 7 & $4(57.1 \%)$ & $3(42.9 \%)$ & 0 \\
$8-$ & 8 & $5(62.5 \%)$ & $2(25.0 \%)$ & $1(12.5 \%)$ \\
$9-10$ & 12 & $8(65.6 \%)$ & $2(18.0 \%)$ & $1(8.33 \%)$ \\
\hline
\end{tabular}

tumour at the time of enucleation than those patients dying in the later peak. In their case any foci of metastases may well be controlled immunologically for a time, but eventually this becomes inadequate and leads to death from the tumour. Another possibility was that metastases were slower growing, but this too may be under immunological control. It might have been shown that the tumours involved in the late mortality peak were of the predominantly spindle type and those in the early peak of the epithelioid or mixed type, and in fact there is a definite trend for this to occur (Tables 3 and 4). This suggests that the metastatic deaths occurring in the second peak tend to be due to slower growing tumours which may or may not be further immunologically controlled. There is also the possibility here that metastases are present prior to enucleation and because of their small size (maybe only a few cells) remain unsuspected, only growing to sufficient size to kill the patient either by the first or second peak in the mortality graph. However, it is strange that the incidence of pretreatment deaths from metastases is so rare even in the face of a wide variation in lengths of history. Further, that there should be 2 peaks related to the event of treatment adds weight to the evidence of tumour handling being involved as Turnbull et al. suggested ${ }^{14}{ }^{15}$ in relation to carcinoma of the large bowel and Fraunfelder et al. ${ }^{16}$ in relation to experiments on hamster eyes and pressure measurements during enucleation on humans.

As can be seen from the death rate curves for some of the different factors under study, certain types of tumours, i.e., large, anterior, nonspindle cell, etc., have marked peaks in comparison with small, posterior, spindle tumours. This also suggests that there is no direct relationship for this latter group to enucleation.

At present such views must still be speculation until there is a sufficient number of nonenucleated patients with similar tumours followed up for long periods, but I feel certain that the evidence which this paper has added to the idea of enucleation being a deleterious prognostic factor in certain tumours should not be overlooked. As suggested by Zimmerman and McLean, ${ }^{5}$ a pooling of all known cases not treated by enucleation on a world-wide basis and a prospective study by many centres are necessary before a definitive answer to this question may be achieved.

The secretarial services of Miss S. Cooper, Charing Cross Hospital, are gratefully acknowledged.

References

1 Laennec RTH. Extrait du mémoire du M. Laennec, sur les mélanoses. Bull Fac Med (Paris) 1806; 2: 24-6.

2 McLean IW, Foster WD, Zimmerman LE. Prognostic factors in small malignant melanomas of choroid and ciliary body. Arch Ophthalmol 1977; 95: 48-58.

3 Zimmerman LE, McLean IW, Foster WD. Does enucleation of the eye containing a malignant melanoma prevent or accelerate the dissemination of tumour cells? Br J Ophthalmol 1978; 62: 420-5.

4 Zimmerman LE, McLean IW. An evaluation of enucleation in the management of uveal melanomas. Am J Ophthalmol 1979; 87: 741-60.

5 Paul EV, Parnell BL, Fraker M. Prognosis of malignant melanomas of the choroid and ciliary body. Int Ophthalmol Clin 1962; 2: 387-402.

6 Packard RBS. M.D. thesis. An investigation into the significance of clinical histopathological and therapeutic factors in the prognosis of malignant choroidal melanoma. University of London, 1978.

7 Ashton N. Malignant tumours of the eye and adnexa. Cancer. London: Butterworth, 1958: 2: 549.

8 Raivio I. Uveal melanoma in Finland-an epidemiological, clinical, histological and prognostic study. Acta Ophthalmol (Kbh) 1977; 48: 5-72.

9 Shammas HF, Blodi FC. Orbital extension of choroidal and ciliary body melanomas. Arch Ophthalmol 1977; 95: 2002-5.

10 Berkson J, Gage RP. Calculations of survival rates for cancer. Mayo Clin Proc 1950; 25 : 270-86.

11 Benjamin B, Cumings JN, Goldmith AJB, Sorsby A. Prognosis in uveal melanoma. Br J Ophthalmol 1948; 32: 729-47. 
12 Jensen OA. Malignant melanomas of the uvea in Denmark 1943-1952. A clinical, histopathological and prognostic study. Acta Ophthalmol (Kbh) 1963; 75: Suppl, 141-392.

13 Siegel D, Myers M, Ferris F, III, Steinhorn SC. Survival rates after enucleation of eyes with malignant melanoma. Am J Ophthalmol 1979; 87: 761-5.

14 Turnbull RB Jr, Kyle K, Watson FR. Cancer of the colon. The influence of the no-touch technique isolation technique on survival rates. Ann Surg 1967; 166: 420-9.

15 Turnbull RB Jr. Current concepts in cancer of the G I tract, colon, rectum, anus. The no-touch isolation technique of resection. JAMA 1975; 231 : 1181-8.

16 Fraunfelder FT, Boozman FW, Wilson RS, Thomas AH. The no-touch technique for intraocular malignant melanomas. Arch Ophthalmol 1978; 95: 1616-20. 